\title{
Research Item s
}

Early Man in China. Further researches and discoveries at Choukoutien, the site of discovery of Peking man, are deseribed in three recent communications to the Geological Society of China. Messrs. Ralph W. Chaney and Lyman H. Daugherty deal with the occurrence of Cercis in association with the remains of Sinanthropus (Bull. 12, No. 3). Fragments of charred wood pointing to the use of fire by Peking man have been identified as a new species of Cercis, a member of the family of Leguminosæ. In honour of the late Davidson Black it is named specifically Blackii ; but it is sufficiently akin to $C$. chinensis, common in Chili Province, to suggest the probability that the climate in Peking man's day was much as it is now. P. Teilhard de Chardin and Dr. W. C. Pei report on discoveries in 1933-34 at Choukoutien (Bull. 13, No. 3) which, while not altering previous conclusions, add distinctness to precedent views on the stratigraphy and physiography of late Cenozoic times in north China. It is now apparent that the Lower Pleistocene, unknown for so long, is one of the most important Cenozoic formations in north China. New localities in the form of pockets have been opened up which make it possible to distinguish five, or even six, stages, instead of the three sedimentary units and the single fossiliferous horizon (Sinanthropus beds) previously differentiated. A preliminary report on the late palæolithic cave is presented by Dr. W. C. Pei (Bull. 13, No. 4) in which the archæological and palæontological finds are described. Five cultural layers were found. Three human skulls and a large series of other human bones were discovered and among the artefacts 28 perforated teeth (canines) of fox or badger, which by their juxtaposition suggest the use of teeth as a necklace. As possibly younger than the remains of southern Ordos and older than Hailar, a tentative dating as equivalent to Magdalenian man in Europe is suggested.

Beehive Graves in the Sudan and Sinai. Mr. G. W. Murray describes and figures in Man of February six beehive tombs, closely resembling the nawamis of Sinai or the rijjum of Arabia, which he discovered in 1926 in the neighbourhood of the fishing village of Halaib on the Red Sea coast. Superstructures had been erected over the original interment by corbelling until a beehive of three metres internal diameter at base and $1.7 \mathrm{~m}$. high had been formed with an aperture in the roof large enough to admit the passage of a man. Outside this a dry stone tumulus six metres in diameter had been piled up rather untidily. The Sinai nawamis differ from the Halaib graves by having a neatly built retaining wall around them. Two graves were examined and in each at about $20 \mathrm{~cm}$. depth very much decomposed bones covered with stones were discovered. The only objects found with them were two copper rings. They appeared to be pre-Islamic, but of no very great antiquity. They recall the more elaborate graves described by Schweinfurth from Gebel Maman. Sinaitic nawamis excavated by Curelly were found to contain shell ornaments and flint arrow-heads belonging to a primitive race, but not necessarily very early in date. Corbelling in mud brick occurs at a very early date in Egyptian tombs. Dr. Reisner, in a private letter which is quoted, refers to Second Dynasty examples and says that he now assigns the use of rude brick corbelling to the last king of Dynasty I. Therefore the practice of corbelling seems to have originated in mud-brick in the Nile Valley about the time of the First Dynasty, to have been copied in rubble masonry by the inhabitants of the desert, and to have spread north-eastward into Sinai and Northern Arabia and south-eastward into the Sudan and Eritræa, where it is not yet quite extinguished by the Moslem type of burial.

Influence of Light upon Goatsucker's Song. Gilbert White shared the general impression that the song of the goatsucker begins "exactly at the close of day", but S. E. Ashmore's observations in Surrey and Glamorgan carried on during three summers, show that there is a considerable amount of variation (British Birds, February, p. 259, 1935). In the course of the day, there are generally two spells of song, one commencing after sunset, the other before sunrise. The former began 18-101 minutes after sunset, the latter between 123 minutes and 27 minutes before sunrise; but the average times respectively are about 35 minutes and 50 minutes. It would seem that light intensity is one factor in determining the song, for the presence of bright moonlight delayed the commencement of the evening song, though it is not so easy to understand why it should have hastened the commencement of the morning song to the extent of more than half an hour before sunrise. Another problem lies in the seasonal variation of the periods, which are longer in mid-July than in June or August, although light conditions are not then at their highest. The author hazards the suggestion that there may be a "connexion with the hour at which are found flying the moths and other creatures which form the bird's food".

Deep-Sea Fishes and a New Trawl. Mr. Eide Parr ("Report on Experimental Use of a Triangular Trawl for Bathypelagic Collecting with an Account of the Fishes obtained and a Revision of the Family Cetomimidae". Bull. Bingham Oceanographic Coll., 4, 1934. Contribution No. 35, Woods Hole Oceanographic Institution) describes a trawl which was successfully used during the first Caribbean cruise of the Atlantis sponsored jointly by the Woods Hole Oceanographic Institution and Yale University. The large triangular trawl, $50 \mathrm{ft}$. long each side of the opening and with three otter boards, was provided by the Bingham Oceanographic Foundation of Yale University. Although difficulties in equipment and arrangements were great, one haul was extremely successful, showing that with certain alterations, easily made on land, this trawl should be a valuable addition in deep-sea collecting to supplement the results obtained by the smaller nets. Many large fish are caught, but not so many small specimens, owing to the coarser mesh. The one successful haul yielded a total of 47 species of fish and 491 individuals, 373 of which belonged to the genus Cyclothone. The author, having examined a large number of samples from the east central Atlantic, concludes that there are only three species of this genus in the area studied-C. braueri, $C$. pallida and $C$. microdon. Several new species are described and a new sub-family and genus. Among the new species is a male Borophryne, agreeing in all essentials with $B$. apogon of Regan and Trewavas, 
but differing in the number of rostral spines and in other minor points. As the author states, "it is thus for the first time possible to introduce a new Ceratoid species referred to its proper genus on the basis of a still unattached male only".

Silicoflagellates and Tintinnids of the Great Barrier Reef. Dr. S. M. Marshall (Great Barrier Reef Expedition 1928-29. Scientific Reports. British Museum (Natural History). 4, No. 15; 1934) shows that silicoflagellates are rare in the material available since their small size enables them to pass through the meshes of the finest net. By centrifuging the water samples it is found that they were present in small numbers, but show no seasonal variation. The Tintinnoinea were captured in the tow-nettings taken with the international fine silk net described by Russell and Colman (2, No. 2 ; 1931). They fall into two groups, those adapted to neritic conditions, and those of oceanic habitat which are restricted to water of relatively high salinity. Neritic species are common throughout the year, but especially in March. Oceanic species are rarer and oceur mainly in August and September from the weekly stations when the salinity inside the barrier was more than 35 per cent. Fifty-six species are recorded, twentytwo being cosmopolitan and known from the Atlantic, Pacific and Indian Oceans, sometimes from temperate and even arctic regions. Nine species are restricted to warm seas. Results from stations on or near the outer reefs suggest that there is a rich tintinnid fauna in the ocean waters outside, of which only some species can live permanently within the barrier. Three species are new to science. Several forms hitherto only known from the eastern tropical Pacific are now recorded from the western Pacific also.

Vegetative Propagation at Edinburgh. For a long time horticulturists have regarded the Edinburgh Botanic Gardens as the place to which to turn for advice and help in matters of plant propagation. This has been largely due to the general willingness of the staff to help, but also to the great interest of the late L. B. Stewart in the problem of vegetative propagation. Dr. R. J. D. Graham, who was closely associated with his work, has now stated briefly some of the main conclusions reached by Stewart during his long struggle with the practical problems associated with vegetative propagation (Trans. Proc. Bot. Soc. Edin., 31, Part 3; 1934). One difficulty is to know when to make the cuttings. A general guide is to take the cutting when the season's growth is completed, when reserve foods for next season's growth are being accumulated and when at the same time vigorous cells capable of wound protection are still present. Stewart had euttings taken of many plants every month, and from these data a list is now published by Dr. R. J. D. Graham showing in what months successful (more than ninety per cent) propagation was obtained.

Potato Diseases in Great Britain. The Ministry of Agriculture and Fisheries has recently issued a new portfolio of "Leaflets on Diseases of Potatoes" as No. 3 of its series of collected leaflets (London : H.M. Stationery Office, pp. 45, 1s. 6d. 1934). This loose-leaflet volume replaces No. 3 of the older sectional volumes, "Cultivation and Diseases of Potatoes". Three leaflets on potato-growing and the selection of seed tubers are omitted, as the subjectmatter is to be expanded into a new bulletin. Six of the original leaflets have recently been revised, and issued as advisory leaflets, in which form they are included in the new portfolio. They deal with common scab, the Colorado beetle, powdery scab, black-leg, mosaic and virus diseases, and dry rot. Advisory leaflet No. 71, on the Colorado beetle, is enriched with a new coloured plate, while there are more half-tone illustrations than formerly. A seventeen-page insert has been printed specially for the new collection, and briefly describes nine miscellaneous diseases, namely, skin spot, spraing, black seurf and stem canker, violet root-rot, white root-rot, pink rot, watery wound rot, Verticillium wilt, and silver scurf. Potato blight, wart, Sclerotinia rot and leafroll diseases, are adequately described by the inclusion of four older leaflets.

Distribution of Earthquakes. A new map by Capt. N. H. Heck of the distribution of earthquakes throughout the world is published in the Geographical Review of January 1935. It is based mainly on the location of epicentres instrumentally determined during the period 1899-1933. To these have been added epicentres of major earthquakes of historical record especially in China, Syria and the Lesser Antilles. The map shows clearly two great belts of activity. Of these, the more striking is the Mediterranean-Pacific belt, which appears to girdle the earth via the Mediterranean, southern Asia, the north Pacific and West Indies, with main branches southward via the Malay Archipelago and New Guinea to New Zealand and from the West Indies into South America. The second belt is that of the mid-Atlantic, and this is entirely oceanic and is marked by few major shocks, but of course there is less scope in this belt for instrumental records. It is noticeable that practically all the great ocean deeps are within the belts and all the largest rifts on the land surface are within the great belt or its branches. There would appear to be no belt crossing the Pacific Ocean, the branch to Easter Island being linked to South America. In the South Atlantic, a detached area around the South Sandwich group may prove to be an extension of the mid-Atlantic belt.

Overhead Irrigation. Investigations into the methods and value of overhead or spray irrigation in Australia have been made at the Commonwealth Research Station at Griffith, New South Wales, and some conclusions are published in Pamphlet No. 50 of the Council for Scientific and Industrial Research, Melbourne ("The Design of Overhead Irrigation Systems", E. S. West and A. Howard). The system depends on the distribution of water under pressure from orifices in lateral pipes branching from the mains. These laterals are 1-in, pipes placed on the ground. They can easily be moved from place to place or rotated to ensure complete irrigation. The advantages of the system compared with surface methods are the greater control over the quantity and distribution of the water, the absence of water-logging which may oecur near irrigation trenches, the lack of need of ditches and levees with a consequent saving of ground and the added possibility of irrigating at will an area not previously prepared, and lastly a great saving in labour. There are, however, some disadvantages in the system, including the initial cost, depreciation of plant and the cost of pumping the water. The authors believe that the spray system is cheaper and more advantageous than surface irrigation on undulating land with light soils, and that the converse is true on heavy flat land. 
Flow of Colloidal Systems. Dr. A. S. C. Lawrence (Proc. Roy. Soc., A, Jan. 1) has examined the flow of colloidal liquids, which do not in general behave as simple viscous liquids. The flow was investigated by suddenly changing the flow through a glass tube from colourless solution to solution containing a dye, and photographing the advancing boundary of colour. This boundary is parabolic for ordinary viscous liquids. The colloidal systems fall into two classes: in one the resistance is small at the wall of the tube, rises rapidly to a maximum and falls off again to the centre of the tube; in the other, the 'gelating' class, the resistance to flow increases as the axis of the tube is approached. Some of the colloidal solutions show very marked elastic properties. The anomalous flow is interpreted as due to the mutual interference of large, non-isodimensional (that is, elongated) micelles.

Absolute Measurement of X-Rays with a Geiger Counter. G. L. Locher and D. P. Le Galley (Phys. Rev., Dec. $15,1934)$ have applied the Geiger-Müller counting tube to the absolute measurement of $\mathrm{X}$-ray intensities. A narrow beam of $\mathrm{X}$-rays is passed through a counter in such a way that only electrons liberated in the gas of the counter are counted. Using krypton at $6.3 \mathrm{~cm}$. pressure and zirconium fluorescent $K$ radiation, the absorption of the rays in the gas column is known to be $3 \cdot 75$ per cent, and since the number of electrons corresponding to this absorption is counted, the number of quanta in the beam may be deduced. The scattering of the beam may be neglected compared with the fluorescent absorption. The beam calibrated in this way was used to obtain the sensitiveness of Eastman X-ray film. The minimum visible blackening was obtained with $7 \cdot 2 \times 10^{5}$ quanta per sq. em. A curve connecting the blackening of the film with the incident quanta is published.

Action of Alternating Magnetic Fields upon Ferromagnetic Particles. About twelve years ago, W. M. Mordey described experiments on the action of single and multi-phase alternating magnetic fields on ferromagnetic particles (see Proc. Phys. Soc., 40, 338 ; 1928). The phenomena observed suggested that under certain conditions there was a repulsion of the particles from strong to weak field regions. Thus when the particles were strewn on a surface above a series of vertical magnets excited alternately by twophase current, they moved in the direction opposite to that of the movement of the successive alternate north and south poles to which the arrangement corresponds. No satisfactory interpretation of the phenomena was given. Further experiments have been made by H. Stafford Hatfield (Proc. Phys. Soc., $46,604 ; 1934)$, using particles of iron, steel, magnetite and pyrrhotite. No anomalous repulsive action was observed when the particles were attached by adhesive to one arm of a torsion balance, or when the particles were allowed to fall freely through the fields. The essential factors involved may be appreciated by considering the effect on a magnetised particle resting on a surface due to a moving vertical magnet, or series of magnets, below the surface. Owing to friction, the horizontal force on either pole of the particle will be effective only when that pole is raised from the surface; that is, after the upward vertical force has passed a definite value. The particle as a whole will, therefore, move oppositely to the magnets below, each pole of the particle stepping out alternately. It is clear that remanent magnetism is necessary for these effects to occur, and that their magnitude will depend on the shape and mass of the particles as well as on their magnetic characteristics. The behaviour of particles under more complex conditions can readily be given on the above basis.

Constitution of Xylan. Previous work on the structure of the polysaccharide xylan revealed that the sub. stance was composed of chains of xylopyranose units linked through the 1-4 positions of the pentose molecule. The glycosidic linkages were known to be $\beta$ in type, and in many ways xylan presented close structural analogies with cellulose. More recent investigations by W. N. Haworth, E. L. Hirst and E. Oliver (J. Chem. Soc., $1917 ; 1934)$ show that xylan prepared from esparto celluloses of different origin is possibly more closely related to the plant gums than to normal cellulose. It contains, in addition to the xylopyranose residues, a fixed and constant proportion of combined $l$-arabinose in the furanose form. This $l$-arabofuranose unit is retained during methylation and the methylated xylan gives on hydrolysis 90 per cent of 2:3-dimethyl xylose and about 6 per cent of $2: 3: 5$-trimethyl $l$-arabofuranose. The last product shows that the arabinose residue must be present in the furanose condition in xylan and that it forms a terminal group attached to a chain of consecutive xylopyranose residues--the first occasion on which the natural occurrence of arabofuranose has been observed. Xylan is non-reducing, and previous experiments by Schmidt in favour of a terminal carboxyl group could not be confirmed. Trimethyl xylose has not been detected in the cleavage products of methylated xylan, and it seems evident that the trimethyl arabofuranose takes the place of this as a terminal group in what is otherwise a series of xylopyranose units. Alternative structures which are possible in the present stage of the investigation are considered.

The Spectroscopic Binary $\zeta$ Aurigae. Work performed at Cambridge at the recent eclipse of the variable $\zeta$ Aurigae is described in the November Monthly Notices R.A.S. This spectroscopic binary is also an eclipsing variable and consists of a $K$ type supergiant and a $B$ star, and has an especial interest since it is the first accurately to give the dimensions and mass of a red supergiant from observations alone. The Cambridge observations consisted of an accurate measurement of the magnitude difference between the normal and eclipsed system, made by Dr. W. M. Smart with a photo-electric photometer. The difference was found to be $2 \cdot 281 \mathrm{~m}$., with the very small probable error of $0.004 \mathrm{~m}$. At the same time, spectroscopic observations were made at the Solar Physics Observatory. These are described by Dr. A. Beer. A remarkable feature is the appearance of the $\mathrm{Ca}+$ lines in absorption in the violet spectrum of the $B$ star when this star emerges from the eclipse. Naturally, these lines are absent from the normal $B$ spectrum, which is readily distinguished from the $K$ spectrum in the violet by its greater intensity. The appearance of the $\mathrm{Ca}+$ lines is due to the passage of the light from the $B$ star through an extensive $\mathrm{Ca}+$ chromosphere or envelope carried by the red star. As the $B$ star moves clear of the eclipsed position, these $\mathrm{Ca}+$ lines decrease in intensity. The distance between the two stars is about $10^{10} \mathrm{~km}$., and their diameters 335 and $2 \frac{1}{2}$ times that of the sun, for the red supergiant and $B$ star respectively. 